\title{
DIGITISATION PROJECTS IN TERTIARY INSTITUTION LIBRARIES IN NORTH-WEST NIGERIA
}

\author{
MOHAMMED M. KPAKIKO AND ALI MUHAMMED FAKANDU
}

\begin{abstract}
This paper is an empirical study that attempted to $x$-ray the digitisation projects in tertiary institution libraries in North-West Nigeria. Usmanu Danfodiyo University, Soloto (UDUS), Wazini Umaru Federal Polytechnic, Birnin Kebbi (WUFP) and Federal College of Education (Technical) Gusau (FCE (T)) were used as a case study. Purposive sampling technique was used to draw five (5) sample staff from Usmanu Danfodiyo University, Sokoto because it has the highest number of staff' for the exercise and three (3) staff' each from Waziri Unaru Federal Polytechnic, Birnin Kebbi and Federal College of Education (Technical), Gusau. Therefore, a total of eleven (11) staff were chosen as the sample for the study. The respondents composed of professional librarians and Management Information System (MIS) staff' of the institutions under study. Eleven (11) structured questionnaires were distributed and all were returned and found usefil for the study. The data collected were analyzed and discussed using frequency table. The findings revealed that digitisation takes place in the libraries under study as the respondents agreed that these libraries are digitising information resources. Problems of inadequate ICT infrastructure, poor digitisation skills by library staff, poor digitisation equipment and inadequate digitisation management skills by the digitisation management stakeholders were discovered as bane to successfiul digitisation projects in the institutions under study. Way forward; such as adequate staff training, finding, procurement of the state-of-the art digitisation equipment etc were recommended.
\end{abstract}

Keywords: Digitization, Tertiary Institutions, Library

\section{Introduction}

In the current digital age, the operations and services of Libraries, Information Centres, Museums and Archives are gradually being replaced with electronic devices and equipments. Tony and Momoh (2012) defined digitisation as "the process of transforming materials from solid manual state into soft visible automatic state." Gbaje (2007) sees digitisation as "a process of converting non digital born documents to digital formats." Digitisation acknowledges the value of a traditional library but it provides better and more enhanced services. Digitisation involves the use of scanner, digital camera and other digital equipments to capture physical or printed images and convert them to digital/electronic format (Anyakoha, 2004). Digitisation enables the library to provide electronic access to local contents in form of full text databases, CD-ROMs and Internet such as World Wide Web (www).

Furthermore, digitisation makes the library virtual in nature by providing remote access to information which was initially consulted physically within the library building. It creates new digital environment, new applications and services as well as new approaches to information provision. Chio and Rasmussen (2006) asserted that modern libraries and information centres are providing a transformative model of large-scale and user-centre services that is moving towards an integrated form within various components. 


\section{Services Offered by Digitisation}

According to Ngwuchukwu (2012) digitisation of library collections opens up varieties of approaches to research in the following ways:

i. Online search: This is a situation whereby the librarian poses a query to a computer on a network and it brings out the answer. This is possible only when there are online databases which are made available by the publishers and vendors such as WILSEARCH, RSC, Science-direct etc.

ii. CD-ROM Search: The librarian and the library customers can access materials directly from the compact disk, read only memory. CD-Rom can be loaded into the computer and the data stored on it can be accessed just like hard copy book.

iii. Telecommunication: This is a device that connects the computer in the library and the databases loaded on main frame computers. The availability of the network allows long distance connection.

iv. E-mail: Electronic mail is one of the services offered by the internet. The library can use this facility to connect to other library schools and exchange ideas for the improvement of its services. It also helps the library to easily place order for books from different vendors, publishers and make payments, interlibrary loan and teleconferencing.

v. Internet: This is a network that links other networks of computers. These computers in the network stores volumes of digitised information and provide unrestricted access to them irrespective of the location.

\section{Benefits of Digitisation}

Digitisation takes different shapes but the most important thing it does is to modify manual way of working for good output. Ngwuchukwu (2012) pointed out the following benefits of digitisation:

i. Speedy and easy access to information;

ii. Access to information remotely;

iii. Access to information 24 hours daily;

iv. Access to unlimited information from different sources;

v. Move to current information;

vi. Facilitating the reformatting and combination of data;

vii. It reduces the time and energy searching for information;

viii. It makes the in-depth search for information more convenient and effective.

\section{Statement of the Problem}

In 2010, digitisation project started in Usmanu Danfodiyo University, Sokoto, Waziri Umaru Federal Polytechnic, Birnin Kebbi and Federal College of Education (Technical), Gusau. Since then, the project has not yielded the desired results. The situation is now receiving the attention of scholars and researchers expressing their concern over the lack of digital contents on the web for global access. It is on the basis of this problem that the study was initiated to 
identify the factors responsible for the failure of these institutions to execute this project. Meaningful suggestions and recommendations are proffered that could help in achieving success.

\section{Objectives of the study}

1. To assess the ICT infrastructure available for digitisation project in tertiary institution Libraries in North-West Nigeria.

2. To find out the skills available for digitisation project in tertiary institution Libraries in North-West Nigeria.

\section{Research Questions}

The study was guided by the following research questions:

1. What are the ICT infrastructures available for digitisation in tertiary institution Libraries in North-West Nigeria?

2. What are the skills available for digitisation project in tertiary institution Libraries in North-West Nigeria?

\section{Justification}

This study was carried in order to create more awareness and consciousness on how to manage the challenges under study that can lead to adequate and satisfactory management of digitisation projects in Nigerian tertiary institution libraries in order to promote quality teaching, learning, show casing the research output to the world and for possible webmetric ranking. When libraries indulge in digitisation of information resources, wastages on frequent technology migration (hardware and software) and waste of funds will be minimized and saved for further growth and improvement of the libraries.

In addition, further contribution of the study to knowledge is that, it will enlighten the digitisation stakeholders to some of the challenges that can make the digitisation unsuccessful. The study will also contribute to the body of knowledge in Nigeria and the world at large especially to the scholars and researchers in Library, Archival and Information Science.

\section{Methodology}

A case study research design was used for this study. This has enabled the researcher to assess the ICT infrastructures and the skills available for digitisation in the institutions under study. The population of the study consists of eleven (11) staff that are directly involved in the digitisation work. Purposive sampling technique was employed due to the small number of staff that is engaged in the digitisation exercise. Five (5) sample staff was drawn from Usmanu Danfodiyo University, Sokoto because it has the highest number of staff involved in the project and three (3) staff each from Waziri Umaru Federal Polytechnic, Birnin Kebbi and the Federal College of Education (Technical), Gusau, Questionnaire was the major 
instrument used to collect data. All questionnaires were completed and returned and found useful for the study. Data collected were presented and discussed using frequency table.

\section{Data Analysis and Discussion of Findings}

Analyses of data were systematically carried out using the research questions and are presented in the tables overleaf:

\begin{tabular}{llllll} 
Table 1: & \multicolumn{6}{c}{ ICT Infrastructures Available for the Digitisation Project } \\
\hline S/No. & Types of ICT infrastructure & UDUS & WUFP & FCET & Total \\
& & & & GUSAU & No. \\
\hline 1. & Functional Internet facility & $\checkmark$ & $\checkmark$ & $\checkmark$ & 3 \\
2. & Complete VSAT and Modem & $\checkmark$ & $\checkmark$ & $\checkmark$ & 3 \\
3. & High-speed workstations & $\checkmark$ & $\checkmark$ & $\checkmark$ & 3 \\
4. & High-speed printer & $\checkmark$ & $\checkmark$ & $\checkmark$ & 3 \\
5. & Data backup facilities & $\checkmark$ & $\checkmark$ & $\checkmark$ & 3 \\
6. & Digital repository software & $\checkmark$ & $\checkmark$ & $\checkmark$ & 3 \\
7. & Functional institutional website & $\checkmark$ & $\checkmark$ & X & 2 \\
8. & Dedicated Bandwidth & $\checkmark$ & $\checkmark$ & X & 2 \\
9. & Functional server computer & $\checkmark$ & $\checkmark$ & X & 2 \\
10. & Functional library portal & X & X & X & - \\
11. & High-speed scanner A4/A3 & X & X & X & - \\
12. & Digital camera & X & X & X & - \\
13. & Script/language recognition software & X & X & X & - \\
\hline
\end{tabular}

Availability or provision of functional ICT infrastructure in the institutions especially in the library is a pre-requisite for achieving a successful digitisation project. From the Table 1 above, it was revealed that the three institutions (Usmanu Danfodiyo University, Sokoto, Waziri Umaru Federal Polytechnic, Birinin Kebbi and Federal College of Education (Technical) Gusau ) have functional Internet facility, complete VSAT and Modem, Highspeed computer workstations, High-speed Printers, Data backup facilities and Digital repository software that can enhance digitisation and dissemination of digital information resources.

From the table 1 above, it was discovered that among the three institutions under study, only 2 (UDUS \& WUFP) have functional institutional website, dedicated bandwidth and functional server computer. Out of these, only UDUS has a fiber optic back bone for a fast and speedy data communication. Similarly, the same 2 institutions (UDUS \& WUFP) has functional server computer currently in use. It was indicated in the Table 1 also, that none of the three institutions under study has a functional library portal, high-speed scanner, digital camera and script/language recognition software. 
Table 2: $\quad$ Types of Skills Available for the Digitisation Project

\begin{tabular}{|c|c|c|c|c|c|}
\hline S/No. & Types of skills required & UDUS & WUFP & $\begin{array}{l}\text { FCET } \\
\text { GUSAU }\end{array}$ & $\begin{array}{l}\text { Total } \\
\text { No. }\end{array}$ \\
\hline 1. & Ability to use various computer hardware & $\checkmark$ & $\checkmark$ & $\checkmark$ & 3 \\
\hline 2. & $\begin{array}{l}\text { Standard file format and assigning } \\
\text { metadata }\end{array}$ & $\checkmark$ & $\checkmark$ & $\checkmark$ & 3 \\
\hline 3. & $\begin{array}{l}\text { Ability to use various digital repository } \\
\text { software packages }\end{array}$ & $\checkmark$ & $\mathrm{X}$ & $\mathrm{X}$ & 1 \\
\hline 4. & Web publishing skills & $\checkmark$ & $\mathrm{X}$ & $\mathrm{X}$ & 1 \\
\hline 5. & Database management skills & $\checkmark$ & $\mathrm{X}$ & $\mathrm{X}$ & 1 \\
\hline 6. & Networking skills & $\checkmark$ & $\mathrm{X}$ & $\mathrm{X}$ & 1 \\
\hline 7. & Digital conversion process & $\checkmark$ & $\mathrm{X}$ & $\mathrm{X}$ & 1 \\
\hline 8. & $\begin{array}{l}\text { Use of tools for digital collection } \\
\text { development }\end{array}$ & $\checkmark$ & $\mathrm{X}$ & $\mathrm{X}$ & 1 \\
\hline 9. & $\begin{array}{l}\text { Knowledge about digitisation of library } \\
\text { resources }\end{array}$ & $\checkmark$ & $\mathrm{X}$ & $\mathrm{X}$ & 1 \\
\hline 10. & Digital preservation techniques & $\checkmark$ & $\mathrm{X}$ & $\mathrm{X}$ & 1 \\
\hline 11. & $\begin{array}{l}\text { Skills to operate different image } \\
\text { capturing } \\
\text { equipment }\end{array}$ & $\mathrm{X}$ & $\mathrm{X}$ & $\mathrm{X}$ & - \\
\hline
\end{tabular}

Table 2 above, indicated that all the librarians that engaged in digitisation work can make effective use of various computer hardware and standard file format and assign metadata. However, only few librarians from UDUS posses the ability to make use of various digital repository software packages such as Dspace, Open Repository, Greenstone etc, has web publishing skills, database management skills, networking skills, skills for digital conversion process and use of tools for digital collection development, knowledge about digitisation of library resources and digital preservation techniques. Table 2 above further revealed that no librarian from the three institutions under study has the complete knowledge of how to operate different image capturing equipment such as scanning machine, digital camera etc.

\section{Summary of Findings}

Based on the data collected, the study revealed that digitisation of local contents in higher institution libraries in North-West Nigeria depends largely on the available ICT infrastructures as was seen in Table 1. Respondents revealed that none of these three institutions has functional library portal, high-speed scanning machines such as scanfeed A3/A4, digital camera and script/language recognition software. The implication of this is that, these facilities are very essential and are necessary equipments for the best digitisation project management practices that can lead to complete execution of digitisation project. It was discovered from Table 2 that majority of the skills required for successful digitisation project are grossly inadequate. Staff skills for digitisation project management has over all responsibilities for all aspects of the work throughout the course of the project. Skills to operate different image capturing equipments is completely lacking in the three institutions under study. The implication of this is that there will be low quality production of digital information resources. 


\section{Conclusion}

Digitisation of information resources in tertiary institution libraries in North-west Nigeria basically assists the institutions to showcase their research output and improve their visibility globally. Although, it is very tasking to achieve the complete execution of the project going by the ICT infrastructural facilities and the available staff skills in these institutions. The success of digitisation projects requires combination of high-speed ICT equipments and staff expertise which are grossly inadequate in the three institutions understudy. Hence the findings have shown that many librarians are ignorant of the digitisation process itself and therefore, require training.

\section{Recommendations}

The following recommendations are offered based on the findings:

i. Tertiary institution libraries in North-West Nigeria where these projects are being embarked upon should be committed to a substantial investment in keeping pace with technology in procuring functional and interoperable digital asset management equipments with ability to adequately manage institution's digital asset.

ii. Management of tertiary institutions under study should see digitisation project as an integral part of the library system and should continue to research into some kind of models that will be used in the training of librarians for digital library projects in Nigeria and in abroad. More importantly, short-time hands-on digitisation training or courses should be awarded to librarians to enable them acquire skills from other libraries who have already advanced in the area of digitisation. 


\section{References}

Anyakoha, M. W. (2004). Information and Communication Technology (ICT) in Library and Information Services. Keynote Address Presented at the Annual Conference of the Nigerian Library Association, Enugu State Chapter ICT. Dec. $1^{\text {st }}-5^{\text {th }}$ Pp 13-15.

Chio, Y. and Rasmussen, E. (2006). What is Needed to Educate Future Digital Librarians Dlib Magazine, 12 (9): 1-9.

Gbaje, E. S. (2007). Digitisation and Challenges: Digital Records and Archival Management Workshop for Members of Federal Capital Territory, Abuja. Archives and History Bureau Committee and Liaison Officers. Arewa House, Kaduna. $3^{\text {rd }}-9^{\text {th }} \mathrm{Pp} 10-11$.

Ngwuchukwu, M. N. (2012). Digitisation of Law Libraries: Implications for Proper Administration of Justice in Nigeria. In Proceedings of Second Professional Summit on Information Science and Technology (PSIST) Nsukka: Nnamdi Azikiwe Library, $3^{\text {rd }}-7^{\text {th }}$ Pp217 - 218.

Tony, I. O. and Momoh, N. J. (2012). Library Digitisation: Avenue for Managing Information-Based Resources in Nigerian University Libraries. In Proceedings of Second Professional Summit on Information Science and Technology (PSIST) Nsukka: Nnamdi Azikiwe Library, $3^{\text {rd }}-7^{\text {th }}$ P 159. 